\title{
Rocío CARAvedo
}

\section{Percepción y variación lingüistica. Enfoque sociocognitivo}

Madrid/Frankfurt a. M.: Iberoamericana/Vervuert

2014, 343 páginas

ISBN 978-84-8489-830-6 (Iberoamericana)

ISBN 978-3-95487-374-6 (Vervuert)

Rocío Caravedo, académica del Dipartimento di Studi Linguistici e Letterari de la Università di Padova, se ha destacado, especialmente en los últimos años, por sus publicaciones acerca de la percepción y de la significación lingüísticas. En su obra más reciente, Percepción y variación lingüistica. Enfoque sociocognitivo, ha intentado acercarse al fenómeno de la percepción mediante la cognición. En este sentido, la percepción servirá "para entender la naturaleza y el funcionamiento de la cognición lingüística" (p. 9) y se transformará en un elemento esencial para entender y explicar la variación de una lengua.

La obra de Caravedo, desde nuestra perspectiva, podría constituir un volumen complementario al publicado por Moreno Fernández en 2012, pues está distribuido en tres partes, a saber, 1) una revisión histórica de las propuestas tradicionales de la variación, 2) una revisión de los conceptos básicos vinculados con la percepción y 3) una aplicación empírica de los conceptos presentados. Es, en lo fundamental, la tercera parte la que funciona como ilustración de la base metateórica desarrollada por Moreno Fernández (2012) y ampliamente discutida y reflexionada por esta autora en las tres partes que conforman su obra.

La primera parte del libro, titulada "La percepción en el concepto tradicional de variación: alcances, límites y propuestas", constituye una completa revisión de la línea tradicional de la teoría variacionista. Así, la autora intenta responder dos preguntas clave, a saber, cómo ha sido percibida la variación y qué rango se le ha asignado en la fenomenología del lenguaje. En esta parte de la obra es sustancial la diferencia entre lo invariable -abordado por las escuelas estructuralistas en sus diversas modalidades- y lo variable - estudiado por líneas como la dialectología, la sociolingüística, la antropología y la etnolingüística-. Asimismo, y desde la propuesta laboviana, cobra relevancia el hecho de que la heterogeneidad, más que la homogeneidad, parece ser el principio universal del lenguaje. Por lo mismo, para entender el fenómeno lingüístico no hay que establecer, según Caravedo, relaciones interdisciplinarias (en el sentido de disciplinas diferentes con objetos también separados), sino que hay que partir de la base de que la estructura de las lenguas es, en sí misma, social, y hay que abordarla como tal. Lo variable y lo invariable, por lo tanto, tienen su fuente en la mente de los hablantes, de manera que la cognición es cardinal para abordar, por una parte, la variación y el cambio $y$, por otra, la invariación.

De manera concreta, la autora refuerza la idea de que la postura rígida de "equivalencias semánticas" no permite acercarse al estudio de las variantes que 
dan origen al cambio lingüístico, que tiene como efecto la creación de nuevos significados. Este es, a nuestro parecer, uno de los aportes más relevantes de la obra, ya que se centra en el cambio antes que en el concepto de variable, que, de acuerdo con Caravedo, no guardaría correspondencia con los procesos reales que guían el proceso de la variación y, en este sentido, lo cognitivo es de suma relevancia. De modo consecuente, en la tercera parte del volumen que reseñamos, la autora se pregunta cómo incide la percepción en la continuación de los patrones variables o invariables del español, o la proyección de los últimos en el cambio. Las posibles respuestas apuntan a que si los hablantes perciben fenómenos determinados y logran, a su vez, valorarlos respecto de sus ideales lingüísticos, podrían controlar la producción y orientar la dirección del cambio estimulándolo o frenándolo. Esta propuesta - desde nuestra perspectiva- se vincula directamente con la noción de cambio desde arriba de Labov (1972). Se trata, en cierto modo, de ampliar el campo de acción del significado representativo, pues "no son entidades externas o independientes de los seres humanos, sino que estos son los que les dan sustento, los interpretan y los usan" (p. 30). Frente a esto y en relación con la labor del lingüista, Caravedo, al igual que Moreno Fernández (2012), propone centrarse en las categorizaciones de los hablantes, a fin de acercarse a su modo de percepción. La premisa fundamental, en este caso, es que la percepción del hablante no debe identificarse necesariamente con la percepción científica, aunque deberían acercarse, si el objetivo central es la lingüística cognitiva. A diferencia de la propuesta laboviana, además, la autora pone de relieve que el lenguaje responde a procesos miméticos complejos y que, en consecuencia, no solo se reproducen y preservan los valores constantes, sino también los singulares. Es, entonces, la cognición del hablante la que se conecta con los fenómenos invariables y con los variables.

"La percepción en la cognición lingüística" es el título que recibe la segunda parte de la obra de Caravedo. Esta segunda parte del libro es, sin duda, la más relevante en términos teóricos. La autora comienza señalando que la cognición alude tanto al conocimiento adquirido de una lengua, como al proceso que se pone en juego para conocerla y utilizarla. Así, la percepción constituye un recurso medular en el proceso de la cognición lingüística. De esta forma, Caravedo vuelve sobre la idea de que variación e invariación tienen carácter cognitivo y ambas se relacionan en todas las etapas del conocimiento lingüístico. En este contexto, se presentan los argumentos de la invariación desde la primera infancia, es decir, la invariación se presenta como objeto primario de percepción, si no hay contraste con otras variedades. Lo relevante, en este caso, es la capacidad de deslindar las formas invariantes de las variantes, y de reproducir selectivamente estas últimas. En consecuencia, el desarrollo de la competencia es el que conduce a la percepción de la variación, primero, estilística y, luego, grupal. En definitiva, solo se puede percibir -desde la cognición- la variación si se confrontan dos formas pertenecientes a dos modelos diferentes: "cognición y percepción terminarán interconectándose e influyéndose recíprocamente” (p. 56).

Le sigue a esta reflexión la exposición de los tres mecanismos implicados en la cognición lingüística y, por ende, en la percepción, a saber, captación, fijación y (re) 
producción. Los dos primeros, a su vez, serán esenciales para generar el conjunto de marcas de identidad. El supuesto base de Caravedo es el de Searle referido a que el conocimiento de una lengua es de naturaleza subjetiva.

El capítulo incluye, asimismo, la revisión del desarrollo de la percepción y enfatiza en que, en materia de lenguaje, va dirigida a la producción (entendida como el input lingüístico del hablante y a su modo de procesarlo) y atañe, en el sentido estricto, a la recepción (referida al output lingüístico, esto es, la actividad discursiva). Se desarrollan en detalle las fases cronológicas de la percepción: a) el periodo adquisitivo, b) el periodo de aprendizaje escolar y c) el periodo estable. De esta manera, se concluye que la percepción cumple una función diferenciadora sirviendo de recurso analítico y discriminativo.

Una de las interrogantes más interesantes de la obra es la que alude a la relación entre el componente social, la afectividad y la pragmática. La pragmática, ligada a la sociabilidad, conecta con la afectividad primaria; el sistema de valores está implicado en el desarrollo pragmático, en la medida en que supone selección (qué decir, a quién, cómo). De esta forma, Caravedo retoma el punto clave de la obra: el lenguaje es de naturaleza social, lo que le permite reflexionar sobre el indisoluble vínculo entre la valoración y la percepción, que es vital, desde la perspectiva de esta autora, en materia de lenguaje.

Esta segunda parte del volumen que reseñamos revisa, además, las tres características fundamentales asignables a la percepción, a saber, selectiva, orientada y diversa. Junto con esto, se incluye un repaso por los tipos de percepción respecto del objeto percibido, esto es, percepción interna, percepción externa y autopercepción, que ya había desarrollado la autora en publicaciones anteriores. A nuestro parecer, en especial la autopercepción permite proponer una estrecha relación con los estudios de identidad, porque es la percepción que va dirigida a la propia variedad, la que implica, por una parte, atribución de valores positivos o negativos al discurso ajeno $\mathrm{y}$, por otra, la posibilidad de autodefinirse positiva o negativamente frente a estas formas discursivas, propiciando o evitando el empleo de ciertas formas lingüísticas ${ }^{1}$. En relación con la percepción interna y la percepción externa, la autora revisa la percepción analítica y sintética. El capítulo finaliza con una reflexión acerca de la percepción del discurso científico, que, a juicio de Caravedo, es ontológicamente de la misma naturaleza perceptiva que la del hablante común.

La tercera parte del libro, "Aplicación empírica", es, tal como su nombre lo sugiere, un soporte empírico a la propuesta teórica presentada en las dos primeras

\footnotetext{
Recordemos que investigadores como Eckert y Rickford (2001) hablan de una construcción de la identidad individual que interactúa tanto con contenidos específicos, como con factores contextuales que producen significados. Asimismo, Niño-Murcia (2011) destaca el papel de la sociolingüística en tanto disciplina que estudia la variación y la identidad en el lenguaje, y explora las diferentes maneras en que la identidad se refleja en diferencias lingüística precisas, como el léxico, la prosodia y la pronunciación.
} 
partes del libro. La síntesis de múltiples estudios propios y de otros investigadores en el contexto de la lingüística hispánica permite que Caravedo logre su cometido de mostrar cómo la variación en la producción de los hablantes de la comunidad hispánica es reflejo de una diversidad perceptiva, tanto ingenua como técnica. En este capítulo se pasa revisión a la percepción fonética, a la sintáctica y léxica, y a la percepción en el contacto lingüístico por migración. Adquiere, así, especial relevancia el concepto de espacios de variabilidad. Luego de exponer variados casos, la autora destaca de qué manera los fenómenos, pese a ser materialmente idénticos, son distintos desde las conciencias normativas sociales, según el sistema referencial desde el cual se los observa. Por consiguiente, sugiere "partir de la observación centrada en el hablante cuya variación se estudia, esto es, de la variación cognitiva intraindividual. Esta actitud se muestra coherente con el supuesto según el cual toda variación normativa es de naturaleza subjetiva" (p. 227). De esta forma, es el sistema cognitivo del hablante el centro de referencia descriptivo. En este orden, es igualmente interesante la forma cómo la autora aborda el nivel discursivo, pues sostiene que en el sistema cognitivo de los hablantes se da una articulación solidaria de los fenómenos lingüísticos de cualquier rango (variables o invariables) con un denominador común funcional de carácter discursivo/comunicativo, de manera que quedan implicados los agentes que construyen los discursos, es decir, todos los niveles son tratados en su realización en el ámbito del discurso.

Para finalizar esta reseña, debemos precisar que se trata de un volumen de lectura compleja, debido a que exige el manejo de una serie de conocimientos previos acerca de la teoría variacionista laboviana. No obstante, de la misma forma que con Moreno Fernández (2012), esta publicación nos permite avanzar en los estudios que abordan la estrecha relación entre la lingüística cognitiva y la sociolingüística o, más precisamente, en los estudios de base sociolingüística en los cuales la percepción sirva para entender la naturaleza y el funcionamiento de la cognición lingüística. Los ejemplos que presenta la autora, en la tercera parte del volumen, dan cuenta de que el hablante es, indudablemente, el creador y transformador de la lengua, ya que, gracias al rol de la percepción, fenómenos lingüísticos en apariencia similares tienen distintos valores porque son percibidos de modo diferente. En este sentido, la obra de Caravedo constituye, de manera incuestionable, un aporte para quienes se interesan por los problemas vinculados con la percepción y la valoración lingüísticas.

Como ya mencionáramos, de gran interés resultan las aproximaciones de Caravedo a los estudios de identidad y el vínculo entre el componente social, el afectivo y el pragmático. En definitiva, creemos que este trabajo, en su conjunto, nos permite avanzar en los estudios de la sociolingüística cognitiva. 


\section{REFERENCIAS BIBLIOGRÁFICAS}

Eckert, Penelope y Rickford John (eds.). 2001. Style and sociolinguistic variation. Cambridge: Cambridge, University Press.

Labov, William. 1972. Sociolinguistic Patterns. Philadelphia: University of Pennsylvania Press.

Moreno Fernández, Francisco. 2012. Sociolingüistica cognitiva. Proposiciones, escolios y debates. Madrid/Frankfurt: Iberoamericana/Vervuert.

Niño-Murcia, Mercedes. 2011. Variation and identity in the Americas. En M. Díaz Campos (ed.), The Handbook of Hispanic Sociolinguistics. Oxford: Blackweel Publishing Ltd.

Silvana Guerrero GonZález

Grupo de Estudio Sociolingüístico del Español de Chile (ESECH)

Universidad de Chile 